\title{
Planning Parenthood: \\ The Affordable Care Act Young Adult Provision and Pathways to Fertility
}

by

\author{
Joelle Abramowitz \\ University of Michigan
}

CES 17-65

November, 2017

The research program of the Center for Economic Studies (CES) produces a wide range of economic analyses to improve the statistical programs of the U.S. Census Bureau. Many of these analyses take the form of CES research papers. The papers have not undergone the review accorded Census Bureau publications and no endorsement should be inferred. Any opinions and conclusions expressed herein are those of the author(s) and do not necessarily represent the views of the U.S. Census Bureau. All results have been reviewed to ensure that no confidential information is disclosed. Republication in whole or part must be cleared with the authors.

To obtain information about the series, see www.census.gov/ces or contact J. David Brown, Editor, Discussion Papers, U.S. Census Bureau, Center for Economic Studies 5K034A, 4600 Silver Hill Road, Washington, DC 20233, CES.Working.Papers@census.gov. To subscribe to the series, please click here. 


\begin{abstract}
This paper investigates the effect of the Affordable Care Act young adult provision on fertility and related outcomes. The expected effect of the provision on fertility is not clear ex ante. By expanding insurance coverage to young adults, the provision may affect fertility directly through expanded options for obtaining contraceptives as well as through expanded options for obtaining pregnancy-, birth-, and infant-related care, and these may lead to decreased or increased fertility, respectively. In addition, the provision may also affect fertility indirectly through marriage or labor markets, and the direction and magnitude of these effects is difficult to determine. This paper considers the effect of the provision on fertility as well as the contributing channels by applying difference-in-differences-type methods using the 2008-2010 and 2012-2013 American Community Survey, 2006-2009 and 2012-2013 Centers for Disease Control and Prevention abortion surveillance data, and 2006-2010 and 2011-2013 National Survey of Family Growth. Results suggest that the provision is associated with decreases in the likelihood of having given birth and abortion rates and an increase in the likelihood of using long-term hormonal contraceptives.
\end{abstract}

Keyword: Fertility, Affordable Care Act, Young Adult Provision, Health Insurance

JEL Classification: I12, I13, I18, J13

\footnotetext{
*Any opinions and conclusions expressed herein are those of the author and do not necessarily represent the views of the U.S. Census Bureau. All results have been reviewed to ensure that no confidential information is disclosed.
} 


\section{Introduction}

The high cost of medical care can cause significant financial strain as well as impede seeking any care: in 2012, 30 percent of adults ages 19-64 reported having trouble paying their medical bills, and 43 percent reported not seeking needed medical care because of cost (Collins et al. 2015). Insurance coverage facilitates individuals and families pursuing medical care to improve their health outcomes. In addition, the effect of insurance coverage may also have more far-reaching effects on their life choices. One avenue through which insurance coverage may have broader effects is through greater access to and affordability of both family planning and reproductive health services as well as pre-natal, birth, and infant care. These choices can in turn affect individuals' education, marriage, career, and health outcomes.

Until recently, young adults exhibited the highest rates of uninsurance, and this lack of insurance limited some individuals from seeking health care services. To address this issue, Congress enacted the Patient Protection and Affordable Care Act (ACA) young adult provision in 2010. The provision requires insurers that cover dependents to continue covering them until they turn 26 , regardless of their marital status, student status, or whether they have children. Under this provision, young adults were given additional opportunities to enroll in their parents' private health insurance plans within 30 days following the first day of the first plan or policy year beginning on or after September 23, 2010. Many insurance companies began covering these individuals voluntarily before this date, as early as May 2010 (U.S. Department of Labor 2013). Prior to the ACA provision, young adults who were not enrolled in school generally became ineligible for coverage under their parents' private health insurance plans when they turned 19 years old, while students generally aged out when they turned 24 years old. Many of these young adults became uninsured upon reaching these age limits. In response, many states passed laws increasing the eligibility age or relaxing eligibility requirements for obtaining coverage under parents' private health insurance plans (Monheit et al. 2011), but these state mandates were not as comprehensive or well-known as the ACA provision.

Recent work found the ACA provision has been effective in increasing health insurance coverage for young adults and has in turn affected their health-related outcomes. With regard to insurance, several papers found that the provision was effective in increasing the number of young adults with any health insurance (Sommers and Kronick 2012; Akosa Antwi, Moriya, and Simon 2013; Sommers et al. 2013; Barbaresco, Courtemanche, and Qi 2015) and with private health insurance (O'Hara and Brault 2013); increasing access to care and in the share of young adults with dependent coverage and a reduction in their uninsured rate (Cantor et al. 2012); as well as increasing rates of health insurance coverage for young adults seeking emergency care (Mulcahy et al. 2013) and decreasing the prevalence of uninsurance among the hospitalized (Akosa Antwi, Moriya, and Simon 2015). Further work has found effects of the provision on health-related outcomes beyond the realm of insurance. For example, Barbaresco, Courtemanche, and Qi (2015) found the provision increased probabilities of having a primary care doctor and excellent selfassessed health as well as decreased body mass index, Akosa Antwi, Moriya, and Simon (2015) found the provision increased inpatient hospitalizations, particularly those related to mental illness, Golberstein et al. (2015) found modest increases in general hospital psychiatric inpatient admissions, and Burns and Wolfe (2016) found some evidence of improved mental health 
outcomes. Abramowitz (2016) found the provision associated with a decrease in the propensity to marry as well as in cohabitation, but an increase in the likelihood of divorce, and Heim, Lurie, and Simon (2017) found the provision to be associated with a decrease in the proportion married using U.S. tax records.

This paper examines how the ACA young adult provision affected the fertility and marital outcomes of young adults. Two papers have examined the effect of the ACA young adult provision on fertility. Ma (2015) examined the effect of the ACA young adult provision on births using birth certificate data. She found that the young adult provision reduced fertility rates by about 5 percent in the first 3 years following the policy change and increased the share of children born to unmarried, minority, or less educated mothers. She also found that the provision encouraged earlier initiation of prenatal care and reduced maternal smoking and pregnancy complications. Heim, Lurie, and Simon (2017) examined the effect of the ACA young adult provision on births using U.S. tax records. Their findings suggest that the ACA young adult provision led to a modest decrease in childbearing. While these papers find a significant effect of the ACA young adult provision on fertility, they do not identify the channels leading to the decrease in fertility. This paper considers those channels.

An expansion in insurance coverage may affect fertility-related outcomes through two direct channels. First, an expansion in insurance coverage lowers the out-of-pocket cost of pre-natal, birth, and infant care for those who want to pursue a family but otherwise could not afford it. This channel facilitates child bearing and could lead to an increase in fertility. However, an expansion in insurance coverage also enables obtaining contraceptives or switching from less reliable or short-term methods to more reliable and longer-term methods. This channel facilitates better family planning and could lead to a decrease in fertility. In addition, greater insurance coverage of abortion could lead to increases in abortion rates, though abortion rates may decrease with greater coverage of contraception.

While the ACA young adult provision may directly affect young adults' fertility outcomes through expanded insurance coverage, the provision may also affect fertility outcomes through indirect channels. For example, young adults may opt for obtaining coverage through parents rather than their own employers. As a result, individuals may choose to work fewer hours or not at all, choose different types or locations of jobs, accept different wages, or choose to enroll in school and invest in human capital. These outcomes could in turn affect their fertility-related choices. Indeed, Akosa Antwi, Moriya, and Simon (2013) and Colman and Dave (2017) found suggestive evidence that the ACA young adult provision led young adults to reduce their labor supply. However, Slusky (2015) did not find effects on labor supply, and Bailey and Chorniy (2016) did not find effects on job mobility. The young adult provision may also have indirect effects through income channels: if an individual previously paid for their own health insurance coverage, but obtains dependent coverage as a result of the provision, they could use that income for other ends, including fertilityrelated decision making. ${ }^{1}$ It may also be the case that the provision affects young adults' fertility outcomes through incentives to marry. Young adults affected by the provision might have less incentive to marry since one avenue for obtaining health insurance is through spousal coverage

\footnotetext{
${ }^{1}$ This channel would be less relevant to the extent that insurers raised premiums to offset the increased coverage of adult children, as found by Depew and Bailey (2015), and that parents passed these costs on to their dependents.
} 
and the young adult provision expanded options for obtaining insurance outside of marriage. With regard to this question, Abramowitz (2016) found the provision to be associated with a decrease in the propensity to marry, and Heim et al. (2015) found the provision to be associated with a decrease in the proportion married. A lower likelihood of marriage may in turn affect individuals' sexual frequency as well as their pregnancy wantedness.

This paper adds to this literature by examining the effect of the ACA young adult provision on different fertility-related channels, including the likelihood of a woman to have had a birth as well as on abortion, pregnancy wantedness, and contraceptive use. I consider the relationship between the ACA young adult provision on birth rates using pooled 2008-2010 and 2012-2013 one-year American Community Survey (ACS) data, on abortions using 2006-2009 and 2012-2013 Centers for Disease Control and Prevention (CDC) abortion surveillance data, and on birth-related outcomes using pooled 2006-2010 and 2011-2013 National Survey of Family Growth (NSFG) data. I perform difference-in-differences-type analyses following the approach outlined by Hahn and Yang (2013), Akosa Antwi, Moriya, and Simon (2013), and Abramowitz (2016). This approach exploits variation across age groups and over time.

The findings of the analysis suggest the ACA young adult provision was associated with decreases in the likelihood of giving birth and having an abortion and an increase in the likelihood of using long-term hormonal contraceptives. The results provide evidence that the provision decreased birth rates and abortion rates as well as suggestive evidence of effects through contraceptive channels.

\section{Effects of Health Insurance and Health-Related Policies on Fertility and Related Behaviors and Outcomes}

There is ample evidence that expansions of insurance coverage have affected fertility. Leibowitz (1990) found the RAND health insurance experiment from the 1970s was associated with temporary increases in pregnancy rates and births. Several papers have examined Medicaid expansions from the 1980s and 1990s (Joyce and Kaestner 1996; Joyce, Kaestner, and Kwan 1998; Zavodny and Bitler 2010; Yelowitz 1994; DeLeire, Lopoo and Simon 2011) and have generally found heterogeneous outcomes for different demographic groups. In more recent work, Apostolova-Mihaylova and Yelowitz (2015) examined effects of the Massachusetts reform on fertility and did not find effects on births for all women, but did find an increase in fertility for married women ages 20-24 and a decrease in fertility for unmarried women of the same ages.

The literature has also examined the effects of different types of health insurance on fertilityrelated behaviors and outcomes. Health insurance coverage has been found to be associated with increased use of prescription contraceptives (Culwell and Feinglass 2007) as well as a lower probability of childbearing among near-poor adolescents (Miller et al. 2013). In particular, Dennis et al. (2012) found that the Massachusetts reform improved access to affordable contraception for low-income women even though they faced new challenges in navigating the system, and Dennis et al. (2009) and Gold (2009) found that family planning community centers helped overcome these navigation obstacles. In addition, health insurance coverage is associated with better prenatal care and birth outcomes (Oberg et al. 1991, Braveman et al. 1993, Currie and Gruber 1997, 
Kaestner 1999, Egerter et al. 2002), and Joyce and Grossman (1990) found prenatal care associated with pregnancy wantedness.

Many papers have found family planning initiatives affect fertility behaviors and outcomes. Kearney and Levine (2009) found that expansion of Medicaid family planning services reduced overall birth rates due to increased contraceptive use, and the expansion has also been found to reduce levels of unprotected sex and increase the use of more effective contraceptive methods (Sonfield and Gold 2011) and decrease the probability of giving birth (Mellor 1998). In addition, Peipert et al. (2012) found that no-cost access to contraception reduced abortion rates and teenage birth rates through the reduction of unintended pregnancy. Further, Mulligan (2015) found that state health insurance mandates for coverage of contraception were associated with an increase in the likelihood of contraception use and a decrease in the abortion rate.

This paper adds to the literature by considering the channels through which the young adult provision may have affected fertility. Unlike Medicaid expansions or the Massachusetts reform, the young adult provision only affected individuals with access to insurance through a parent's private plan, representing a much different population. Since the different channels affected by the provision could lead to opposite effects on fertility, it is important to examine these channels to identify the mechanisms driving these effects.

\section{Data}

Examining the effects of the ACA on individuals' fertility and related outcomes requires data covering the periods before and after provision enactment and implementation for treated young adults and a control group. An ideal dataset would have a large sample size and include information on a respondent's fertility history rather than only information on whether a respondent has children in the household. In addition, an ideal dataset would have information on a respondent's feelings and actions related to fertility prior to becoming pregnant and upon becoming pregnant. Since no one dataset has all of these characteristics, I use several datasets to examine these different outcomes: the ACS, CDC abortion surveillance data, and the NSFG. The ACS includes information on whether the respondent gave birth in the 12 months prior to the survey and is large enough to provide reliable subgroup analyses. The CDC abortion surveillance provides annual data by state and age group on abortions for most states. The NSFG, while smaller than the ACS, provides more detailed information on fertility-related preferences and behaviors. ${ }^{2}$

\subsection{American Community Survey}

I pool 2008-2010 and 2012-2013 one-year restricted use ACS data to examine the effect of the ACA dependent coverage mandate on an individual's probability of having given birth. The ACS is a nationwide survey conducted continuously throughout each year. It is conducted in all U.S. counties and Puerto Rico municipios. About 3 million housing unit addresses are sampled

\footnotetext{
${ }^{2}$ While the NSFG also includes data on abortions, such data are known to be underreported and are not recommended for use in substantive research (U.S. Department of Health and Human Services 2014). Accordingly, the CDC abortion surveillance data are used in this analysis for examining effects of the provision on abortion outcomes.
} 
annually, in addition to a sample of individuals living in group quarters such as college dormitories. The restricted use ACS data provide a larger sample than public use data (U.S. Census Bureau 2015) and include additional variables, such as the date the respondent completed the survey. The large sample size serves as an important benefit of the ACS for this analysis. Another benefit is that, although the ACS is a cross-sectional sample, the survey includes a question on fertility timing, providing insight into changes in an individual's fertility over time.

The primary outcome of interest examined in this analysis is whether a woman gave birth in the 12 months prior to the survey response, and I also examine this outcome in light of effects on marriage (whether a woman married in the 12 months prior to the survey response) and marital fertility (whether a woman reported being currently married and having given birth in the 12 months prior to the survey response). I include data beginning in 2008 and not earlier because information on marital history is only available beginning in the 2008 survey. The sample is restricted to include only women. The sample includes women from all U.S. states and the District of Columbia living in households or college dormitories. Active duty military are excluded from the sample. Only responses collected before May 1, 2010 or after June 30, 2012 are included in the analysis to clearly identify pre- and post-provision implementation periods that take into account the dates of the enactment and implementation of the young adult provision, the typically 9-month lag between conceiving and giving birth, as well as the 12-month windows of the fertility and marriage outcome variables. Women ages 20-25 and 28-30 at the time of survey response are included in the analysis; women ages 26 and 27 are excluded to identify clear effects for the treatment age group of 20-25.

I use data from the 2008-2010 and 2012-2013 survey years to examine the periods before and after provision implementation. The period before provision implementation covers January 1, 2008 through April 30, 2010 and the implementation period covers July 1, 2012 through December 31, 2013. With the typical 9 months between conception and birth, births occurring during the analysis pre-implementation period should have been conceived before both provision enactment (May 2010) and implementation (September 2010), while births occurring during the analysis implementation period should have been conceived after both provision enactment and implementation. Likewise, marriages occurring during the analysis pre-implementation period should have occurred before both provision enactment and implementation, while marriages occurring during the analysis implementation period should have occurred after both provision enactment and implementation. A woman is classified in a period based on her survey response date, available in the internal ACS data. Table 1 presents summary statistics for the full ACS analysis sample. The likelihood of having given birth increases with age, and the proportion in school decreases with age. In general, younger age groups tend to be more diverse in terms of race/ethnicity than older age groups.

\subsection{Centers for Disease Control and Prevention Abortion Surveillance}

I pool 2006-2009 and 2012-2013 CDC abortion surveillance data to examine the effects of the ACA young adult provision on abortion rates. The CDC compiles data on legally induced 
abortions from states and reporting areas that conduct abortion surveillance. ${ }^{3}$ Data are publicly available by state and age group. I include data for the following age groups: ages 15-19, 20-24, and 25-29. While the age groups used in the abortion surveillance data do not exactly correspond to the age groups treated by the young adult provision, they are generally consistent. I include data beginning in 2006 to be consistent with the periods covered by the NSFG data, discussed subsequently.

The outcome of interest examined in this analysis is the annual state-age-group abortion rate. This rate is calculated as the number of abortions in a given state in a given year for women in a given age group divided by the number of women in that age group living in that state in that year, in thousands. The sample includes all states reporting abortion rates in a given year. I exclude data for 2010 and 2011 to clearly identify pre- and post-provision implementation periods that take into account the dates of the enactment and implementation of the young adult provision and the time between conception and termination. Table 2 presents population-weighted averages for abortion rates by age group over the full sample analysis period and before and after the implementation of the young adult provision.

\subsection{National Survey of Family Growth}

I pool individual-level data from the 2006-2010 and 2011-2013 rounds of the NSFG to examine the effects of the ACA young adult provision on several fertility-related outcomes. Each round of the NSFG interviews a nationally representative sample of men and women ages 15-44 living in households in the United States.

The primary outcomes of interest examined in this analysis include feelings toward wantedness of pregnancy and contraceptive use/type. The sample used in this analysis is limited to include only women ages 16-18, 20-25, and 28-30 who were not pregnant at the time of the survey; again, women ages 19,26, and 27 were excluded to identify clear effects for the treatment age group of 20-25.

Data from the 2006-2010 NSFG and 2011-2013 NSFG are used to examine the periods before and after provision implementation. The periods of data collection facilitate analysis of the effect of the ACA young adult provisions: the 2006-2010 NSFG interviews were conducted from June 2006 through June 2010, and the 2011-2013 NSFG interviews were conducted from September 2011 through September 2013. Accordingly, data from the 2006-2010 NSFG comprise the period before provision implementation while data from the 2011-2013 NSFG comprise the period after provision implementation.

Table 3 presents summary statistics for the full NSFG sample, all women ages 16-18, 20-25, and 28-30 who were not pregnant at the time of the survey. The proportion trying to become pregnant, the proportion working full time, and the proportions with their own children in the household increases with age. 16-18 year-olds are the least likely to use any contraceptives. All age groups

\footnotetext{
${ }^{3}$ Specifically, California, Florida, New Hampshire, and Wyoming did not report in any of the sample years and Delaware, the District of Columbia, Louisiana, Maine, Maryland, and Vermont did not report in all years.
} 
have generally similar proportions of individuals by race/ethnicity, income, and metropolitan area categories.

\section{Methods}

To estimate the effects of the young adult provision on fertility and related outcomes, it is necessary to identify the effects of the provision separately from other factors that might affect fertility occurring over the same period. Since the provision applies only to young adults ages 1925 , this analysis generally compares outcomes for individuals in the treatment age group to outcomes for similarly aged individuals at ages not covered by the provision before and after provision enactment and implementation. This approach assumes that individuals in the control group face similar trends in fertility and related outcomes as the treatment group and thus will account for time-varying factors that would have resulted in different rates of outcomes after the enactment and implementation of the provision for the treatment group.

I use two different approaches to accommodate the constraints of the datasets used in the analysis. I use an individual-level model to examine fertility and fertility-related outcomes in the ACS and NSFG, and I use a state-year-age-group-level model to examine abortion rates in CDC abortion surveillance data.

\subsection{Overview of Individual-Level Model}

The individual-level analysis compares outcomes for a treatment group of young adults ages 2025 to a control group. For the ACS analyses, I perform estimations using a control group of slightly older women ages 28-30. For the NSFG analyses, I perform estimations using a control group of both slightly younger women ages 16-18 and slightly older women ages 28-30 for increased sample size. Individuals ages 19, 26, and 27 were excluded from both sets of analyses to identify clear effects for the treatment age group of 20-25. Whether slightly younger women should be included in the control group is not clear ex ante: on the one hand, women younger than those at ages affected by the provision may better reflect the circumstances of younger women in the treatment age group and provide greater sample size, especially for the NSFG analyses; on the other hand, a control group of only individuals in their twenties may better reflect the circumstances of the young adults at ages affected by the provision with regard to making choices about fertility, insurance, and employment. Ultimately, for this paper's analyses, women ages 1618 were not included in the ACS control group because they exhibited differential trends in fertility prior to provision enactment; they were included in the NSFG control group because they did not exhibit statistically differential trends in the abortions, pregnancy wantedness, or contraceptive use prior to provision enactment. Results from the NSFG analyses including only older women in the control group and results from the ACS analyses including younger women in the control group were generally found to be quantitatively similar as were results of both sets of analyses limited to ages 22 and older.

The ages and years of data used in the analysis take into consideration the concern that individuals who appear in the sample in the older control group may have been affected by the provision when they were younger. By including individuals ages 28 and older in the control group and including only data through 2013, the vast majority of individuals in the control group should have already 
been 26 years old in 2011, the main year of the implementation of the young adult provision. Including younger individuals in the control group of these individuals might bias the results toward finding a negative effect of the provision on birth rates if individuals delayed fertility from the affected ages to older ages.

\subsection{Overview of State-Age-Group-Level Model}

The state-age-group-level analysis compares annual state abortion rates for a treatment group of women ages 20-24 to those for a control group of both slightly younger women ages 15-19 and slightly older women ages 25-29. 19-year-olds and 25-year-olds were affected by the provision but are included in the control group because these age groups represent the most specific age categories publicly available in the CDC abortion surveillance data. To the extent that individuals at these ages were affected by the provision, including them in the control group would bias the results toward zero, representing a lower bound on the effect of the provision on abortion rates. Given the considerations discussed earlier, analyses are performed both with and without the group of slightly younger women.

\subsection{Assumptions and Specifications}

To identify effects of the provision, it is necessary for both the treatment and the control groups to have exhibited similar trends in fertility and related outcomes before the enactment of the provision. To examine the extent to which treatment- and control-group trends were similar prior to the enactment of the provision, Fig. 1 presents the proportion of women that reported giving birth in the 12 months prior to the survey by age group over 2008-2013, and Fig. 2 shows the number of abortions per 1,000 women by age group from CDC abortion surveillance reports over 2006-2013. Fig. 1 shows that prior to provision implementation over 2008 through 2010, prior 12-month birth rates fell for all age groups, and the decrease for 20-25-year-olds was not statistically significantly different the decrease for 28-30-year-olds. While birth rates continued to fall for all age groups over the implementation period from 2011 through 2013, treated 20-25 year-olds experienced a larger decrease than either 16-18-year-olds or 28-30-year-olds. Again, Fig. 2 shows trends in abortion rates were similar across age groups prior to provision enactment. However, beginning in 2010, 20-24-year-old women experienced a disproportionate decrease in abortion rates compared younger and older women.

To formally test for equality of trends, I conduct a falsification test using data covering the preimplementation period for each dataset. I estimate the main analysis model, described subsequently, for each outcome, except the key variable of interest here is an interaction between the linear time trend and the treatment age group dummy. Results of these specifications, reported in Appendix 1 and Appendix 2, suggest that, conditional on control variables included in the model, there is no statistically significant difference in the control and treatment age groups' trends in outcome variables prior to provision enactment.

While the patterns evident in Fig. 1 and Fig. 2 are suggestive of a relationship between the provision and fertility-related outcomes, it is important to control for other factors that might affect this relationship. Thus, a more in-depth analysis of this question is warranted. 


\subsubsection{Individual-Level Specification}

The following difference-in-differences regression model estimates the effect of the young adult provision on individual-level fertility and fertility-related outcomes:

$$
\begin{gathered}
y_{\text {iajt }}=\beta_{0}+\beta_{1} \text { Implement }_{\text {ajt }}+\beta_{2}\left(\text { TreatedAge }_{a} \times \text { Implement }_{\text {ajt }}\right)+\beta_{3} \text { State }_{j} \\
+\beta_{4} \text { Year }_{t}+\beta_{5} \text { TreatedAge }_{a}+\beta_{6} X_{i}+\beta_{7} Z_{j t}+\varepsilon_{\text {iajt }}
\end{gathered}
$$

where $y_{i a j t}$ is a dummy variable equal to one if an individual $i$ of age group $a$ living in state $j$ during survey year $t$ reports having each of the fertility-related outcomes of interest and is equal to zero otherwise. The coefficient on the interaction term $\beta_{2}$ captures the associated difference in the probability of each outcome for a person in the treatment age group during the provision implementation period relative to a person in the control age group, or a person in the treatment age group in the pre-enactment period, holding other characteristics constant. Vectors of parameters are included to control for state fixed effects $\left(\beta_{3}\right)$, year fixed effects $\left(\beta_{4}\right)$, and treatment age-group fixed effects $\left(\beta_{5}\right){ }^{4}$ State fixed effects are omitted from the NSFG analyses since state information is not publicly available in the NSFG. The $\mathrm{X}$ vector $\left(\beta_{6}\right)$ controls for individual demographic characteristics. For the ACS analysis, following Abramowitz (2016), I include dummy variables for age, race/ethnicity, and student status. ${ }^{5,6}$ For the NSFG analysis, following Mulligan (2015), I include dummy variables for age, race/ethnicity, employment status, education attainment, metro status, household income, and the number of own children in the household. ${ }^{7}$ The $\mathrm{Z}$ vector $\left(\beta_{7}\right)$ controls for state-year-level conditions including the age-specific state-year unemployment rate, calculated using the ACS, corresponding to the year prior to the survey year, the interaction of the unemployment rate with the control for the treatment age group, and statespecific linear time trends. The inclusion of age-specific state-year unemployment rates and their interaction with the control for age group are used to identify the effect of the provision separate from lingering effects of the Great Recession, which lasted from December 2007 through June 2009 , and to capture differential effects of the recession by age group since younger adults were particularly hard-hit by the recession. Controls for state-specific linear time trends, the agespecific state-year unemployment rate, and the interaction of the unemployment rate with the

\footnotetext{
${ }^{4}$ Specifications used in this analysis include state fixed effects to account for differences across states. These include differences in state mandates for young adult insurance coverage on parents' private health insurance plans prior to the ACA young adult provision and state health insurance mandates for contraception coverage, as well as other policies and characteristics. Specifications including a control for whether the individual would have been eligible for dependent coverage on a parent's private health insurance plan prior to the ACA young adult provision following the classification of state policies in Monheit et al. (2011) yielded qualitatively similar results. In addition, specifications including a control for whether the state had adopted a dependent coverage mandate prior to the enactment of the ACA young adult provision following the classification of state policies in Monheit et al. (2011) yielded qualitatively similar results.

${ }^{5}$ Including controls for family income as a percentage of the federal poverty line and its squared term resulted in qualitatively similar results.

${ }^{6}$ Incorporating information on parents' insurance coverage into the analysis to identify individuals eligible for coverage through parents as a result of the provision was not used in this analysis investigating fertility because this methodology would limit the sample to only individuals living in the same household as their parents.

${ }^{7}$ These controls were included in individual-level specifications by Mulligan (2015); omitting potentially endogenous controls for employment status, education attainment, household income and the number of own children in the household resulted in qualitatively similar results.
} 
control for the treatment age group are omitted from the NSFG analyses since state information is not publicly available in the NSFG, but a national linear time trend is included. The error term is represented by $\varepsilon$.

The outcomes examined in the ACS analyses include the likelihood of having given birth in the prior 12 months. The outcomes examined in the NSFG analyses include the likelihood of trying to get pregnant in the past three months and the likelihood of using different types of contraceptives over the past 12 months.

In all tables and regressions, the data are weighted to be population-representative. In all ACS regressions, per Bertrand et al. (2004), White robust standard errors clustered by state are used to control for serial correlation among the outcomes and the policy changes of interest. ${ }^{8}$

\subsubsection{State-Age-Group-Level Specification}

The following difference-in-differences regression model estimates the effect of the young adult provision on abortion rates:

$$
\begin{gathered}
y_{a j t}=\beta_{0}+\beta_{1} \text { Implement }_{\text {ajt }}+\beta_{2}\left(\text { TreatedAge }_{a} \times \text { Implement }_{\text {ajt }}\right)+\beta_{3} \text { State }_{j} \\
+\beta_{4} \text { Year }_{t}+\beta_{5} \text { TreatedAge }_{a}+\beta_{6} Z_{a j t}+\varepsilon_{\text {ajt }}
\end{gathered}
$$

where $y_{a j t}$ represents the abortion rate for age group $a$ in state $j$ during year $t$. The coefficient on the interaction term $\beta_{2}$ captures the associated difference in the abortion rate for the treatment age group during the provision implementation period relative to the control age group, or the treatment age group in the pre-enactment period, holding other characteristics constant. Vectors of parameters are included to control for state fixed effects $\left(\beta_{3}\right)$, year fixed effects $\left(\beta_{4}\right)$, and treatment age-group fixed effects $\left(\beta_{5}\right)$. Akin to the state-year-level specifications by Mulligan (2015), the $\mathrm{Z}$ vector $\left(\beta_{7}\right)$ controls for state-year-age-group-level conditions including median household income, the unemployment rate, the average number of children per household, the average number of children less than age 5 per household, percentage of the population that is married, percentage of the population that is nonwhite, percentage of the state with high school and college diplomas, the median age of women, as well as state-specific linear time trends. Stateage-group-level controls are calculated using the 2006-2013 public use ACS and are weighted to be population representative. The error term is represented by $\varepsilon$.

In all regressions, the data are weighted to be population-representative of the female population for each state, year, and age group in the analysis sample using population estimates from the public use ACS. Per Bertrand et al. (2004), White robust standard errors clustered by state are used to control for serial correlation among the outcomes and the policy changes of interest.

\footnotetext{
${ }^{8}$ Linear probability models are used in all regressions rather than probit models for ease of interpretation. Regressions using probit models yielded qualitatively similar results.
} 


\section{Results}

\subsection{Fertility}

Results of the fertility analysis, presented first in Table 4, show a significant negative effect of the ACA young adult provision on 20-25 year-olds' likelihood of having given birth in the prior 12 months. Provision implementation is found to be associated with decreases in the probability of having given birth of 0.95 percentage points, representing a 10.0 percent decrease in the fertility rates of 20-25 year-olds as compared to before provision enactment. ${ }^{9}$

To put these results in context, I use the estimated effects of the provision on birth rates to calculate the number of individuals affected by the provision as proportions of the populations of interest, those gaining dependent coverage through parental employer-sponsored insurance as a result of the provision, with calculations presented in Appendix 3. The decrease in birth rates represents approximately 125,000 fewer births in each year of implementation. ${ }^{10}$ To estimate the potential extent of the fertility effects of the provision on the young adult women who gained dependent coverage through parental employer-sponsored insurance as a result of the provision, I must make assumptions about both the extent of the effect of the provision on insurance coverage as well as the fertility rates of young adult women who gained coverage as compared to young adult women who did not. Using the estimate from Akosa Antwi, Moriya, and Simon (2013) that the provision was associated with a 10.2 percentage point increase in parent employer-sponsored insurance dependent coverage over October-November 2011, I find that in a given year, approximately 1,300,000 20-25-year-old women gained insurance coverage as dependents on parents' employersponsored insurance plans because of provision implementation. ${ }^{11}$ To the extent that fertility rates of young adult women who gained coverage are the same as those of young adult women who did not, the results suggest the mandate was associated with a 98 percent decrease in births in a given year among the population gaining coverage associated with the provision. However, to the extent that fertility rates of young adult women gaining coverage were higher than those of young adult women who did not, the percent decrease would be smaller. For example, assuming young adult women gaining coverage were approximately twice as likely to give birth in a given year as compared to young adult women who did not gain coverage (for example, 18.5 percent of young adult women gaining coverage giving birth in a given year as compared to 8.5 percent of young adult women who did not gain coverage), the results suggest the mandate was associated with a 50 percent decrease in births in a given year among the population gaining insurance coverage associated with the provision.

We may also see differential effects of the provision on fertility by characteristics across which disparities exist in access to health insurance in general and private health in particular. I first explore whether the effects of the provision on fertility vary by race and ethnicity, estimating the analysis separately for non-Hispanic Whites, non-Hispanic Blacks, and Hispanics, with results presented next in Table 4. Results of these analyses show significant decreases in fertility rates for non-Hispanic Whites only; results for non-Hispanic Blacks and Hispanics are smaller in

\footnotetext{
9 The birth rate for 20-25-year-old women before provision enactment was 9.5 percent.

${ }^{10}$ A decrease in the birth rate of 0.95 percentage points on a basis of approximately 13 million women ages $20-25$ would result in approximately 125,000 fewer births.

${ }^{11}$ Calculated as a 10 percentage point increase on a basis of approximately 13 million women ages 20-25.
} 
magnitude and are not significant. These results do suggest differential effects of the mandates by race and ethnicity, with the most prominent effects for non-Hispanic Whites. This is not surprising given that non-Hispanic Whites are the racial/ethnic group most likely to have private health insurance coverage (Smith and Medalia 2015) and only young adults with access to coverage through a parent with private coverage can be affected. These results are consistent with the findings of Akosa Antwi, Moriya, and Simon (2013) of a higher increase in parental-employerdependent coverage for Whites. I next explore whether the effects of the provision on fertility vary by metropolitan status since rural families have historically faced higher rates of uninsurance rates than urban families (Ziller et al. 2008), estimating the analysis separately for individuals living in a metropolitan statistical area (urban) and those living outside a metropolitan statistical area (rural), with results presented subsequently in Table 4. Results of these analyses show significant decreases in fertility rates across metropolitan status, which are consistent with the findings of Look et al. (2016) that did not find differential effects of the young adult provision on health insurance coverage by metropolitan status.

\subsection{Marriage and Fertility Channels}

Having found the provision associated with a decrease in fertility, I next consider the potential channels driving this decrease. One potential channel is marriage. Abramowitz (2016) found a significant negative effect of the provision on the propensity to marry and argued that the decrease in entry into marriage was due to fewer individuals marrying in order to obtain spousal health insurance coverage. If women are less likely to pursue childbearing out of wedlock or if unmarried women engage in less sexual activity than married women, it may then follow that some of the decrease in fertility found in this analysis was attributable to the decrease in marriage. However, it could also be argued that the decrease in marriage was actually driven by the decrease in fertility to the extent that individuals marry in response to an unplanned pregnancy and the provision decreased unplanned births by expanding affordability of contraceptives and, in some cases, abortions.

To examine the extent to which a decrease in marriage resulting from unplanned pregnancies drives this paper's fertility results and Abramowitz's (2016) finding that the provision was associated with a decrease in marriage, I use the ACS to compare the estimated magnitudes of the effects of the provision on marrying (the likelihood of having married in the prior 12 months) and on concurrent entry into marriage and fertility (the likelihood of both having married and having given birth in the prior 12 months). To perform these analyses, I use the same analysis sample, only changing the outcome of interest, in order to compare outcomes for the same individuals. To the extent that the provision resulted in a decrease in marriage as a result of an unplanned pregnancy, we would see a decrease in concurrent entry into marriage and fertility, which represents an upper bound on the effect of the provision on women marrying as a result of an unplanned pregnancy since it includes both women who became pregnant and married shortly thereafter as well as women who married and became pregnant shortly thereafter.

Results, presented in Table 5, show a much smaller magnitude decrease ( 0.1 percentage points $)$ in concurrent entry into marriage and fertility than in entry into marriage ( 0.6 percentage points), and, as discussed earlier, some of the decrease in concurrent entry into marriage and fertility may be accounted for by fertility soon after marrying. Accordingly, while a decrease in marriage in response to an unplanned pregnancy may account for some of the decrease in marriage, it cannot 
explain all of it, consistent with the hypothesis of Abramowitz (2016) that some individuals marry in order to obtain insurance coverage and by expanding access to coverage, some women chose not to marry. Likewise, the decrease in concurrent entry into marriage and fertility does not appear to drive the decrease in fertility found in this paper's analysis.

\subsection{Fertility-Related Outcomes}

Having found an effect of the provision on the birth rates of young adults, I examine the fertilityrelated channels driving this result. For women who want to become pregnant, the provision may facilitate births by providing for lower out-of-pocket costs of pre-natal care and giving birth. However, for women who do not want to become pregnant, the provision may facilitate preventing births by lowering the out-of-pocket costs of contraception, and in some cases, abortion.

Table 6 presents results for the effects of the provision on abortion rates. Results show decreases in abortion rates associated with age groups generally affected by the provision as compared to those associated with age groups not affected by the provision. These results suggest that the increase in insurance coverage is not leading to an increase in abortions, but rather a decrease in abortions, and accordingly, the decrease in fertility is not driven by an increase in abortions.

Table 7 presents results for the effects of the provision on outcomes related to pregnancy wantedness, including whether the respondent was trying to become pregnant in the last three months and contraceptives use in the last 12 months. Results for the likelihood of trying to become pregnant in the last three months are positive and large in magnitude, but are not significant. This result is suggestive that some women are induced to seek a pregnancy as a result of the provision, but the lack of significance limits drawing conclusions from this result.

Results for any contraceptive use, presented subsequently in Table 7, are small in magnitude and insignificant, but these results mask changes in the type of contraceptives used. To consider whether the young adult provision affected type of contraceptives use, Table 7 next presents these results. Results do show a significant increase in the use of long-term hormonal contraceptives including shots and implants. Results for intrauterine devices (IUD) and short-term hormonal contraceptives (the birth control pill, patch, ring) are generally small in magnitude and are not significant, but results for nonhormonal contraceptives (condoms and other barrier methods, withdrawal) are negative and large in magnitude, though again, not significant. These results are suggestive of women switching to using long-term hormonal contraceptives from using nonhormonal contraceptives. Given that long-term hormonal contraceptives are much more effective at preventing pregnancy than nonhormonal contraceptives, these results are consistent with the findings of a decrease in births. In particular, nonhormonal contraceptive use is associated with relatively high rates of unintended pregnancy: for example, diaphragm use is associated with a 12 percent unintended pregnancy rate in a year of typical use, condom use is associated with an 18 percent unintended pregnancy rate in a year of typical use, and other nonhormonal contraceptive methods are associated with even higher unintended pregnancy rates. In contrast, the use of shots and implants are each associated with 6 percent and 0.5 percent unintended pregnancy rates in a year of typical use (Centers for Disease Control and Prevention 2017). The findings of this paper's analysis could reflect some women opting for long-term hormonal methods over less reliable methods as a result of having insurance coverage of these methods. 


\subsection{Placebo Analysis}

It may be the case that the results of the main analysis simply reflect spurious effects arising from the structure of the data or the model specification used in the analysis. To consider this concern, I follow the approach of Slusky (2015), Barbaresco, Courtemanche, and Qi (2015) and Abramowitz (2016) using the same data and specification as in the main analysis to estimate a placebo analysis for which I should not see significant effects of the provision. To do this, I consider a placebo mandate for alternative years prior to provision enactment. Using the ACS, the placebo pre-enactment period covers the 2008 survey year, and I construct the placebo provision period to cover the 2009 and 2010 survey years. Using CDC abortion surveillance data and the NSFG, the placebo pre-enactment period covers 2006 and 2007, and I construct the placebo provision period to cover 2008 and 2009. Table 8 presents results for the placebo analyses. Results generally show no significant effect of the placebo provision. ${ }^{12}$

\section{Discussion and Conclusions}

This paper examined the relationship between the ACA young adult provision and fertility and related outcomes. The findings suggest that the provision was associated with a decrease in the likelihood of having given birth, a decrease in the abortion rate, and an increase in the likelihood of using long-term hormonal contraceptives. The positive result for the likelihood of trying to become pregnant is suggestive that some women are induced to seek a pregnancy as a result of the provision, but the lack of significance limits drawing conclusions from this result.

These results provide evidence that the provision decreased birth rates and abortion rates and suggest effects through contraceptive channels. The finding of a decrease in fertility suggests that the insurance channels facilitating pregnancy prevention outweigh those facilitating pregnancy. This could come about because, as Ma (2015) suggests, prior to the introduction of the ACA young adult provision, uninsured women could generally gain Medicaid coverage once they became pregnant, so the added benefit of private coverage was not as effectual. However, in addition to contraceptive channels, the decrease in fertility may be driven by the decrease in marriage, as marriage is associated with increased pregnancy wantedness as well as increased frequency of sex.

Considering the potential contribution of a decrease in marriage in response to an unplanned pregnancy with respect to previous findings of a decrease in marriage associated with the provision, I find a much smaller magnitude decrease in concurrent entry into marriage and fertility than in entry into marriage. It follows that while a decrease in marriage in response to an unplanned pregnancy may account for some of the decrease in marriage, it cannot explain all of it, consistent with the hypothesis of Abramowitz (2016) that some individuals marry in order to obtain insurance coverage and by expanding access to coverage, some women chose not to marry.

\footnotetext{
12 Barbaresco, Courtemanche, and Qi (2015) and Abramowitz (2016) also consider a placebo treatment group of individuals at ages unaffected by the provision over the analysis period. I also performed such a placebo test, including only individuals ages 28-30 and 32-34, who are outside of the age range affected by the provision, and defined individuals ages 28-30 as the placebo treatment group. However, I could not rule out differential pretreatment trends for the respective age groups.
} 
The results suggest that the increase in insurance coverage is not leading to an increase in abortions, but rather, a decrease in abortions. Accordingly, the decrease in fertility is not driven by an increase in abortions. The decrease in abortions may be driven by the changes in the types of contraceptive use. Alternatively, the decrease may be driven by an increase in birth wantedness potentially arising from greater insurance coverage of pre-natal, birth, and infant care.

The results of this analysis have implications for considering the effects on fertility of full implementation of the ACA as well as future policies related to health insurance. In 2014, ACA state Medicaid expansions, insurance exchanges and subsidies, and the individual mandate to obtain health insurance coverage began to be implemented. State Medicaid expansions provide health insurance coverage to many low-income individuals otherwise unable to obtain it. New health insurance exchanges and subsidies make it easier for individuals to purchase coverage directly and for small businesses to offer coverage to their employees. The individual mandate requires that most Americans obtain health insurance by 2014 or pay a tax penalty.

Like the ACA young adult provision, both state Medicaid expansion and insurance exchanges and subsidies have the potential to decrease fertility directly by providing new avenues for obtaining health insurance, and in turn increasing access to contraceptives. However, these new avenues for obtaining health insurance also provide greater access to pre-natal, birth, and infant care. Effects of these policies are likely to differ from those of the young adult provision since the populations eligible to obtain coverage through a parent's employer-sponsored insurance, eligible for Medicaid expansion, and eligible for coverage and subsidies through exchanges exhibit different age, fertility preferences, and prior health insurance coverage options.

The results of this analysis also have implications for considering the effects on fertility of the ACA contraceptive mandate. The results are suggestive that greater access to contraceptives through such a mandate could be associated with decreased fertility. It follows that limiting the breadth of such a mandate could lead to increases in unplanned pregnancies and births as well as increases in abortions.

The results of this analysis find a decrease in fertility for the treatment age group in the short term, but it is not clear whether the effect will persist over the longer term. The provision may be associated with young adults delaying fertility if it simply enables them to better plan their timing of fertility. Alternatively, by facilitating improved family planning, the provision may decrease the total number of births to women by the end of their childbearing years over the long term.

This study makes several contributions. The results shed light on the relationship between health insurance coverage and fertility and increase understanding of how changes in policies related to insurance can influence fertility behaviors and outcomes. Other papers have explored how Medicaid expansions, Medicaid family planning services expansions, and the Massachusetts reform, among others, affect individuals' fertility behaviors and outcomes. This paper explores the channels through which the ACA young adult provision affected fertility. Finally, the results add to the body of research measuring the effects of the ACA young adult provision. While other papers have found effects of the provision on insurance, labor market, health outcomes, access to care, marriage, and fertility in general, this research explores the channels through which the provision influenced individuals' fertility-related behaviors and outcomes. 


\section{Acknowledgements}

I am grateful to Ausmita Ghosh, Catherine Massey, and three anonymous referees for their invaluable comments and to Sara Zobl for excellent research assistance. I would also like to thank seminar participants at Dickinson College, the University of Michigan Survey Research Center, and the 2016 American Society of Health Economists Biennial Conference for their helpful feedback.

\section{Compliance with Ethical Standards}

The author declares that they have no conflict of interest.

\section{References}

Abramowitz J (2016) Saying, "I don't": The effect of the Affordable Care Act young adult provision on marriage. J Hum Resour, 51(4):933-960

Akosa Antwi Y, Moriya A, Simon K (2013) Effects of federal policy to insure young adults: Evidence from the 2010 Affordable Care Act's dependent-coverage mandate. Amer Econ J: Econ Pol 5(4):1-28

Akosa Antwi Y, Moriya A, Simon K (2015) Access to health insurance and the use of inpatient medical care: Evidence from the Affordable Care Act young adult mandate. J Health Econ 39:171-187

Barbaresco S, Courtemanche C, Qi Y (2015) Impacts of the Affordable Care Act dependent coverage provision on health-related outcomes of young adults. J Health Econ 40:54-68

Bertrand M, Duflo E, Mullainathan S (2004) How much should we trust differences-indifferences estimates? Quart J Econ 119(1):249-275

Braveman P, Bennett T, Lewis C, Egerter S, Showstack J (1993) Access to prenatal care following major Medicaid eligibility expansions. J Amer Med Assoc 269(10):1285-1289

Burns ME, Wolfe BL (2016) The effects of the Affordable Care Act adult dependent coverage expansion on mental health. J Ment Health Policy 19(1):3-20

Cantor J, Monheit A, DeLia D, Lloyd K (2012) Early impact of the Affordable Care Act on health insurance coverage of young adults. Health Serv Res 47(5):1773-1798

Centers for Disease Control and Prevention (2017) Effectiveness of Contraceptive Methods. https://www.cdc.gov/reproductivehealth/contraception/unintendedpregnancy/pdf/contrace ptive_methods_508.pdf. Accessed 1 March 2017

Collins S, Rasmussen P, Doty M, Beutel S (2015) The rise in health care coverage and affordability since health reform took effect: Findings from the Commonwealth Fund biennial health insurance survey, 2014. The Commonwealth Fund, New York 
Colman G, Dave D (2017) It's about time: Effects of the Affordable Care Act dependent coverage mandate on time use. NBER Working Paper 21725.

Culwell KR, Feinglass J (2007) The association of health insurance with the use of prescription contraceptives. Perspectives on Sexual and Reproductive Health 39(4):226-230

Currie J, Gruber J (1997) The technology of birth: Health insurance, medical interventions, and infant health. NBER Working Paper 5985

Dennis A, Clark J, Córdova D, McIntosh J, Edlund K, Wahlin B, Blanchard K (2012) Access to contraception after health care reform in Massachusetts: A mixed-methods study investigating benefits and barriers. Contraception 85(2):166-172

Dennis A, Córdova D, Blanchard K, Wahlin B (2009) Low-income women's access to contraception after Massachusetts health care reform. IBIS Reproductive Health and MDPH Family Planning Program.

Depew B, Bailey J (2015) Did the Affordable Care Act's dependent coverage mandate increase premiums? J Health Econ 41:1-14

Egerter S, Braveman P, Marchi K (2002) Timing of insurance coverage and use of prenatal care among low-income women. Amer J Pub Health 92(3):423-427

Golberstein E, Busch SH, Zaha R, Greenfield SF, Beardslee WR, Meara E (2015) Effect of the Affordable Care Act's young adult insurance expansions on hospital-based mental health care. Amer J Psychiatry 172(2):182-189

Gold R (2009) Family planning centers meet health care reform: Lessons from Massachusetts. Guttmacher Pol Rev 12(3)

Hahn Y, Yang H (2013) Do work decisions among young adults respond to extended dependent coverage? Monash University working paper

Heim B, Lurie I, Simon K (2017) The impact of the Affordable Care Act young adult provision on childbearing, marriage, and tax filing: Evidence from tax data. NBER Working Paper 23092

Jatlaoui TC, Ewing A, Mandel MG, Simmons KB, Suchdev DB, Jamieson CJ, Pazol K (2016) Abortion Surveillance - United States, 2013. Morbidity and Mortality Weekly Report Surveillance Summaries 65(12):1-44

Joyce T, Kaestner R (1996) The effect of expansions in Medicaid income eligibility on abortion. Demogr 33(2):181-192.

Joyce T, Kaestner R, Kwan F (1998) Is Medicaid pronatalist? The effect of eligibility expansions on abortions and births. Family Planning Perspectives 108-127 
Joyce T, Grossman M (1990) Pregnancy wantedness and the early initiation of prenatal care. Demogr 27(1):1-17

Kaestner R (1999) Health insurance, the quantity and quality of prenatal care, and infant health. Inquiry 36(2):162-175

Kearney M, Levine, P (2009) Subsidized contraception, fertility, and sexual behavior. Rev Econ Stat 91(1):137-151

Leibowitz A (1990) The response of births to changes in health care costs. J Hum Resour 25(4):697-711

Look KA, Kim NH, Arora P (2016) Effects of the Affordable Care Act's dependent coverage mandate on private health insurance coverage in urban and rural areas. J Rural Health. doi: $10.1111 /$ jrh. 12183

Ma J (2015) Health insurance and fertility decisions: Evidence from Affordable Care Act young adult provision. Unpublished manuscript

Mellor JM (1998) The effect of family planning programs on the fertility of welfare recipients: Evidence from Medicaid claims. J Hum Resour 33(4):866-895

Miller JA, Graefe DR, De Jong GF (2013) Health insurance coverage predicts lower childbearing among near-poor adolescents. J Adolescent Health 53:749-755

Monheit A, Cantor J, DeLia D, Belloff D (2011) How have state policies to expand dependent coverage affected the health insurance status of young adults? Health Services Res 46(1):251-267

Mulcahy A, Harris K, Finegold K, Kellermann A, Edelman L, Sommers B (2013) Insurance coverage of emergency care for young adults under health reform. New England J Med 368(22):2105-2112

Mulligan K (2015) Contraception use, abortions, and births: The effect of insurance mandates. Demogr 52(4):1195-1217

O'Hara B, Brault M (2013) The disparate impact of the ACA-dependent expansion across population subgroups. Health Services Res 48(5):1581-1592

Oberg CN, Lia-Hoagberg B, Skovholt C, Hodkinson E, Vanman R (1991) Prenatal care use and health insurance status. J Health Care Poor U 2(2):270-291

Peipert J, Madden T, Allsworth J, Secura G (2012) Preventing unintended pregnancies by providing no-cost contraception. Obstetrics and Gynecology 120(6) 1291-1297

Slusky, DJG (2015) Significant placebo results in difference-in-differences analysis: The case of the ACA's parental mandate. East Econ J 1-24 
Smith JC, Medalia C (2015) Health insurance coverage in the United States: 2014. U.S. Census Bureau, Washington

Sommers B, Kronick R (2012) The Affordable Care Act and insurance coverage for young adults. J Amer Med Assoc 207(9):913-914

Sommers B, Buchmueller T, Decker S, Carey C, Kronick R (2013) The Affordable Care Act has led to significant gains in health insurance and access to care for young adults. Health Affairs 32(1):165-174

Sonfield A, Gold RB (2011) Medicaid family planning expansions: Lessons learned and implications for the future. Guttmacher Institute, New York

U.S. Census Bureau (2014) Annual estimates of the resident population by single year of age and sex for the United States: April 1, 2010 to July 1, 2013. http://factfinder.census.gov/faces/tableservices/jsf/pages/productview.xhtml?src=bkmk. Accessed 7 February 2015

U.S. Census Bureau (2015) Frequently asked questions: I'm using the American Community Survey (ACS) Public Use Microdata Sample (PUMS) files. Why don't my estimates match what's published on American Factfinder (AFF)? https://ask.census.gov/faq.php?id=5000\&faqId=911. Accessed 3 March 2015

U.S. Department of Health and Human Services (2014) Public use data file documentation: 2011-2013 National Survey of Family Growth. https://www.cdc.gov/nchs/data/nsfg/nsfg_2011-2013_userguide_maintext.pdf. Accessed 14 April 2017

U.S. Department of Labor, Employee Benefits Security Administration (2013) Frequently asked questions, young adults and the Affordable Care Act: Protecting young adults and eliminating burdens on businesses and families. http://www.dol.gov/ebsa/faqs/faqdependentcoverage.html. Accessed 14 November 2013

Ziller EC, Coburn AF, Anderson NJ, Loux SL (2008) Uninsured rural families. J Rural Health 24(1):1-11 
Tables

Table 1: ACS Summary Statistics

\begin{tabular}{|lcc|}
\hline & Ages 20-25 & Ages 28-30 \\
\cline { 2 - 3 } Proportion Gave Birth in Last 12 Months & 0.089 & 0.114 \\
& $(0.276)$ & $(0.316)$ \\
Proportion White, Not Hispanic & 0.588 & 0.585 \\
& $(0.479)$ & $(0.488)$ \\
Proportion Black, Not Hispanic & 0.144 & 0.135 \\
& $(0.341)$ & $(0.339)$ \\
Proportion Hispanic & 0.185 & 0.189 \\
& $(0.378)$ & $(0.388)$ \\
Proportion Other Race & 0.083 & 0.091 \\
Proportion in School & $(0.268)$ & $(0.285)$ \\
& 0.417 & 0.145 \\
Observations & $(0.480)$ & $(0.349)$ \\
& 629,300 & 319,600 \\
\hline
\end{tabular}

Source: 2008 through 2010 and 2012 through 2013 1-year ACS data, excluding responses reported from May 2010 through June 2012. Notes: The sample includes women from all U.S. states and the District of Columbia living in households or college dormitories who are not active duty military. Standard deviations in parentheses. Numbers of observations are rounded to the nearest hundred. 
Table 2: CDC Abortion Surveillance Abortion Rates, 2006-2009 and 2012-2013

\begin{tabular}{|lccc|}
\hline & Ages 15-19 & Ages 20-24 & Ages 25-29 \\
\cline { 2 - 4 } Abortion Rate 2006-2009, 2012-2013 & 11.8 & 26.5 & 20.4 \\
& $(6.1)$ & $(10.9)$ & $(8.9)$ \\
Abortion Rate 2006-2009 & 12.9 & 27.9 & 21.0 \\
& $(6.3)$ & $(11.4)$ & $(9.4)$ \\
Abortion Rate 2012-2013 & 8.6 & 22.5 & 18.6 \\
& $(4.1)$ & $(8.6)$ & $(7.3)$ \\
\hline
\end{tabular}

Source: 2006-2009 and 2012-2013 CDC abortion surveillance data. Note: Standard deviations in parentheses. 
Table 3: NSFG Summary Statistics

\begin{tabular}{|c|c|c|c|}
\hline \multirow{3}{*}{ Proportion Trying to Become Pregnant in Last Three Months } & Ages 16-18 & Ages $20-25$ & Ages 28-30 \\
\hline & 0.005 & 0.049 & 0.078 \\
\hline & $(0.072)$ & $(0.209)$ & $(0.274)$ \\
\hline \multirow[t]{2}{*}{ Proportion Using Any Contraceptives } & 0.339 & 0.655 & 0.586 \\
\hline & $(0.489)$ & $(0.463)$ & $(0.502)$ \\
\hline \multirow[t]{2}{*}{ Proportion Using Short-term Hormonal Contraceptives } & 0.125 & 0.295 & 0.210 \\
\hline & $(0.341)$ & $(0.444)$ & $(0.415)$ \\
\hline \multirow[t]{2}{*}{ Proportion Using Long-term Hormonal Contraceptives } & 0.025 & 0.056 & 0.054 \\
\hline & $(0.162)$ & $(0.224)$ & $(0.230)$ \\
\hline \multirow[t]{2}{*}{ Proportion Using IUDs } & 0.009 & 0.047 & 0.068 \\
\hline & $(0.095)$ & $(0.206)$ & $(0.256)$ \\
\hline \multirow[t]{2}{*}{ Proportion Using Nonhormonal Contraceptives } & 0.273 & 0.398 & 0.303 \\
\hline & $(0.460)$ & $(0.476)$ & $(0.468)$ \\
\hline \multirow[t]{2}{*}{ Proportion White, Not Hispanic } & 0.203 & 0.179 & 0.189 \\
\hline & $(0.415)$ & $(0.373)$ & $(0.399)$ \\
\hline \multirow[t]{2}{*}{ Proportion Black, Not Hispanic } & 0.537 & 0.584 & 0.586 \\
\hline & $(0.515)$ & $(0.480)$ & $(0.502)$ \\
\hline \multirow[t]{2}{*}{ Proportion Hispanic } & 0.140 & 0.140 & 0.143 \\
\hline & $(0.358)$ & $(0.338)$ & $(0.357)$ \\
\hline \multirow[t]{2}{*}{ Proportion Other Race } & 0.120 & 0.097 & 0.082 \\
\hline & $(0.335)$ & $(0.288)$ & $(0.279)$ \\
\hline \multirow[t]{2}{*}{ Proportion Working Full Time } & 0.082 & 0.400 & 0.514 \\
\hline & $(0.283)$ & $(0.477)$ & $(0.510)$ \\
\hline \multirow[t]{2}{*}{ Proportion Working Part Time } & 0.251 & 0.274 & 0.161 \\
\hline & $(0.448)$ & $(0.434)$ & $(0.375)$ \\
\hline \multirow[t]{2}{*}{ Proportion not Working } & 0.667 & 0.326 & 0.324 \\
\hline & $(0.487)$ & $(0.456)$ & $(0.477)$ \\
\hline \multirow[t]{2}{*}{ Proportion with Some High School Education or Less } & 0.773 & 0.111 & 0.142 \\
\hline & $(0.433)$ & $(0.306)$ & $(0.356)$ \\
\hline \multirow[t]{2}{*}{ Proportion High School Graduate } & 0.203 & 0.252 & 0.238 \\
\hline & $(0.416)$ & $(0.423)$ & $(0.434)$ \\
\hline \multirow[t]{2}{*}{ Proportion Some College } & 0.024 & 0.449 & 0.310 \\
\hline & $(0.159)$ & $(0.484)$ & $(0.471)$ \\
\hline \multirow[t]{2}{*}{ Proportion College Degree or More } & & 0.188 & 0.309 \\
\hline & & $(0.380)$ & $(0.471)$ \\
\hline \multirow[t]{2}{*}{ Proportion in Principal City of MSA } & 0.295 & 0.406 & 0.333 \\
\hline & $(0.471)$ & $(0.478)$ & $(0.480)$ \\
\hline \multirow[t]{2}{*}{ Proportion in Other MSA } & 0.528 & 0.421 & 0.475 \\
\hline & $(0.516)$ & $(0.481)$ & $(0.509)$ \\
\hline \multirow[t]{2}{*}{ Proportion Not in MSA } & 0.177 & 0.173 & 0.192 \\
\hline & $(0.394)$ & $(0.368)$ & $(0.402)$ \\
\hline Proportion with Family Income $<\$ 20,000$ & 0.316 & 0.327 & 0.260 \\
\hline & $(0.480)$ & $(0.457)$ & $(0.447)$ \\
\hline Proportion with Family Income $\$ 20,000-\$ 34,999$ & 0.277 & 0.278 & 0.271 \\
\hline & $(0.462)$ & $(0.436)$ & $(0.453)$ \\
\hline Proportion with Family Income $\$ 40,000-\$ 74,999$ & 0.229 & 0.255 & 0.266 \\
\hline & $(0.434)$ & $(0.424)$ & $(0.450)$ \\
\hline Proportion with Family Income $>=\$ 75,000$ & 0.177 & 0.139 & 0.204 \\
\hline & $(0.395)$ & $(0.337)$ & $(0.411)$ \\
\hline Proportion with No Own Children in Household & 0.961 & 0.704 & 0.378 \\
\hline & $(0.200)$ & $(0.444)$ & $(0.494)$ \\
\hline Proportion with 1 Own Children in Household & 0.036 & 0.173 & 0.214 \\
\hline & $(0.192)$ & $(0.368)$ & $(0.418)$ \\
\hline Proportion with 2 Own Children in Household & 0.003 & 0.086 & 0.220 \\
\hline
\end{tabular}




\begin{tabular}{|lccc|} 
& $(0.054)$ & $(0.273)$ & $(0.422)$ \\
Proportion with 3 or More Own Children in Household & 0.000 & 0.037 & 0.188 \\
& $(0.017)$ & $(0.184)$ & $(0.398)$ \\
Observations & 1,994 & 3,718 & 2,035 \\
\hline
\end{tabular}

Source: 2006-2010 and 2011-2013 NSFG data. Note: Standard deviations in parentheses. 
Table 4: ACS Regression Results for Probability of Having Given Birth in Prior 12 Months

\begin{tabular}{|c|c|c|c|c|c|c|}
\hline & All & $\begin{array}{l}\text { White, Not } \\
\text { Hispanic }\end{array}$ & $\begin{array}{l}\text { Black, Not } \\
\text { Hispanic }\end{array}$ & Hispanic & Rural & Metro \\
\hline Treatment*Implementation & $\begin{array}{c}-0.0095 * * \\
(0.0038)\end{array}$ & $\begin{array}{c}-0.0111 * * * \\
(0.0031)\end{array}$ & $\begin{array}{c}-0.0064 \\
(0.0083)\end{array}$ & $\begin{array}{c}0.0034 \\
(0.0068)\end{array}$ & $\begin{array}{c}-0.0114^{*} \\
(0.0057)\end{array}$ & $\begin{array}{c}-0.0083^{* *} \\
(0.0039)\end{array}$ \\
\hline Observations & 948,900 & 608,500 & 103,300 & 150,300 & 171,000 & 777,900 \\
\hline \multicolumn{7}{|l|}{ Dependent Variable Means } \\
\hline Treatment, Pre-Enactment & 0.0952 & 0.0811 & 0.1260 & 0.1310 & 0.1360 & 0.0880 \\
\hline Control, Pre-Enactment & 0.1190 & 0.1190 & 0.1070 & 0.1300 & 0.1280 & 0.1180 \\
\hline Treatment, Implementation & 0.0787 & 0.0674 & 0.1020 & 0.1030 & 0.1150 & 0.0732 \\
\hline Control, Implementation & 0.1070 & 0.1090 & 0.0915 & 0.1100 & 0.1130 & 0.1060 \\
\hline
\end{tabular}

Source: 2008 through 2010 and 2012 through 2013 1-year ACS data, excluding responses reported from May 2010 through June 2012. Notes: Shown are coefficients estimated from the specification of the determinants of the probability of having given birth in the prior 12 months. Each column presents results from a single regression. Regressions are estimated using population weights. Specifications include state, year, and age fixed effects, national and stateyear trends, as well as individual demographic controls, and the age-specific state-year unemployment rate. The sample includes all women from all U.S. states and the District of Columbia living in households or college dormitories who are not active duty military ages 2030 , excluding women ages 26 and 27, except as noted. Robust standard errors clustered at the state level in parentheses, $* * * \mathrm{p}<0.01, * * \mathrm{p}<0.05, * \mathrm{p}<0.1$. Numbers of observations are rounded to the nearest hundred. 
Table 5: ACS Regression Results for Probability of Having Married in Prior 12 Months versus Having Married and Having Given Birth in Prior 12 Months

\begin{tabular}{|lcc|}
\hline & $\begin{array}{l}\text { Married } \\
\text { Married in } \\
\text { Prior 12 } \\
\text { Months }\end{array}$ & $\begin{array}{l}\text { Birth in } \\
\text { Prior 12 } \\
\text { Months }\end{array}$ \\
\cline { 2 - 3 } Treatment*Implementation & $-0.0059^{* *}$ & -0.0011 \\
& $(0.0024)$ & $(0.0007)$ \\
Observations & 948,900 & 948,900 \\
& & \\
Dependent Variable Means & & \\
Treatment, Pre-Enactment & 0.0497 & 0.0082 \\
Control, Pre-Enactment & 0.0464 & 0.0049 \\
Treatment, Implementation & 0.0421 & 0.0063 \\
Control, Implementation & 0.0489 & 0.0047 \\
\hline
\end{tabular}

Source: 2008 through 2010 and 2012 through 2013 1-year ACS data, excluding responses reported from May 2010 through June 2012. Notes: Shown are coefficients estimated from the specification of the determinants of the probability of having married in the prior 12 months or having married and having given birth in the prior 12 months. Each column presents results from a single regression. Regressions are estimated using population weights. Specifications include state, year, and age fixed effects, national and state-year trends, as well as individual demographic controls, and the age-specific state-year unemployment rate. The sample includes all women from all U.S. states and the District of Columbia living in households or college dormitories who are not active duty military ages 20-30, excluding women ages 26 and 27 . Robust standard errors clustered at the state level in parentheses, $* * * p<0.01, * * p<0.05, *$ $\mathrm{p}<0.1$. Numbers of observations are rounded to the nearest hundred. 
Table 6: CDC Abortion Surveillance Regression Results for Abortions Per Thousand Women

\begin{tabular}{|lcccc|}
\hline & $2006-2013$ & & $2008-2013$ & \\
\cline { 2 - 5 } Treatment*Implementation & Ages 15-29 & Ages 20-29 & Ages 15-29 & Ages 20-29 \\
\cline { 2 - 5 } & $-2.5858^{* * *}$ & $-4.0527^{* * *}$ & $-2.7021^{* * *}$ & $-3.8722^{* * *}$ \\
Observations & $(0.4946)$ & $(0.4319)$ & $(0.4701)$ & $(0.3936)$ \\
& 816 & 544 & 540 & 360 \\
Dependent Variable Means & & & & \\
Treatment, Pre-Enactment & 29.03 & 29.03 & 28.33 & 28.33 \\
Control, Pre-Enactment & 17.61 & 21.55 & 17.20 & 21.12 \\
Treatment, Implementation & 22.50 & 22.50 & 22.50 & 22.50 \\
Control, Implementation & 13.62 & 18.58 & 13.62 & 18.58 \\
\hline
\end{tabular}

Source: 2006-2009 and 2012-2013 CDC abortion surveillance data. Notes: Shown are coefficients estimated from the specifications of the determinants of the annual state-age-group abortion rate calculated as the number of abortions per thousand women. Each column presents results from a single regression. Regressions are estimated using weights corresponding to the state-year-age-group female population using population estimates from the public use ACS. Specifications include state, year, and age group fixed effects, national and state-year trends, as well as state-year-age-group demographic and economic controls. The sample includes abortion rates for women ages 15-29, except as noted. Robust standard errors clustered at the state level in parentheses, ${ }^{* * *} \mathrm{p}<0.01,{ }^{* *} \mathrm{p}<0.05,{ }^{*} \mathrm{p}<0.1$. 
Table 7: NSFG Regression Results for Fertility-Related Outcomes

\begin{tabular}{|lcccccc|}
\hline & $\begin{array}{l}\text { Trying to } \\
\text { Become } \\
\text { Pregnant in } \\
\text { Last } 3 \\
\text { Months }\end{array}$ & $\begin{array}{l}\text { Any } \\
\text { Contraceptive } \\
\text { Use in Last } \\
\text { 12 Months }\end{array}$ & $\begin{array}{l}\text { Use of } \\
\text { Pill, Patch, } \\
\text { or Ring in } \\
\text { Last 12 } \\
\text { Months }\end{array}$ & $\begin{array}{l}\text { Use of Shot } \\
\text { or Implant } \\
\text { in Last 12 } \\
\text { Months }\end{array}$ & $\begin{array}{l}\text { Use of } \\
\text { IUD in } \\
\text { Last 12 } \\
\text { Months }\end{array}$ & $\begin{array}{l}\text { Use of } \\
\text { Nonhormonal } \\
\text { Contraceptives } \\
\text { in Last 12 } \\
\text { Months }\end{array}$ \\
\cline { 2 - 7 } Treatment*Implementation & 0.0108 & -0.0089 & 0.0048 & $0.0264 *$ & 0.0038 & -0.0436 \\
& $(0.0165)$ & $(0.0330)$ & $(0.0291)$ & $(0.0142)$ & $(0.0133)$ & $(0.0329)$ \\
Observations & 7,332 & 7,332 & 7,332 & 7,332 & 7,332 & 7,332 \\
& & & & & & \\
Dependent Variable Means & & & & & & \\
Treatment, Pre-Enactment & 0.0420 & 0.6642 & 0.3085 & 0.0417 & 0.0350 & 0.4170 \\
Control, Pre-Enactment & 0.0405 & 0.4659 & 0.1811 & 0.0386 & 0.0280 & 0.2860 \\
Treatment, Implementation & 0.0552 & 0.6464 & 0.2815 & 0.0707 & 0.0591 & 0.3783 \\
Control, Implementation & 0.0427 & 0.4604 & 0.1541 & 0.0407 & 0.0481 & 0.2894 \\
\hline
\end{tabular}

Source: 2006-2010 and 2011-2013 NSFG data. Notes: Shown are coefficients estimated from the specification of the determinants of the probability of trying to become pregnant in the last three months and the probability of contraceptive use in the last 12 months. Each column presents results from a single regression. Regressions are estimated using population weights. Specifications include year and age fixed effects and national year trends, as well as individual demographic controls. The sample includes all women ages 16-30, excluding women ages 19, 26 , and 27, who were not pregnant at the time of the survey. Standard errors in parentheses, *** $\mathrm{p}<0.01, * * \mathrm{p}<0.05, * \mathrm{p}<0.1$. 
Table 8: Placebo Regression Results

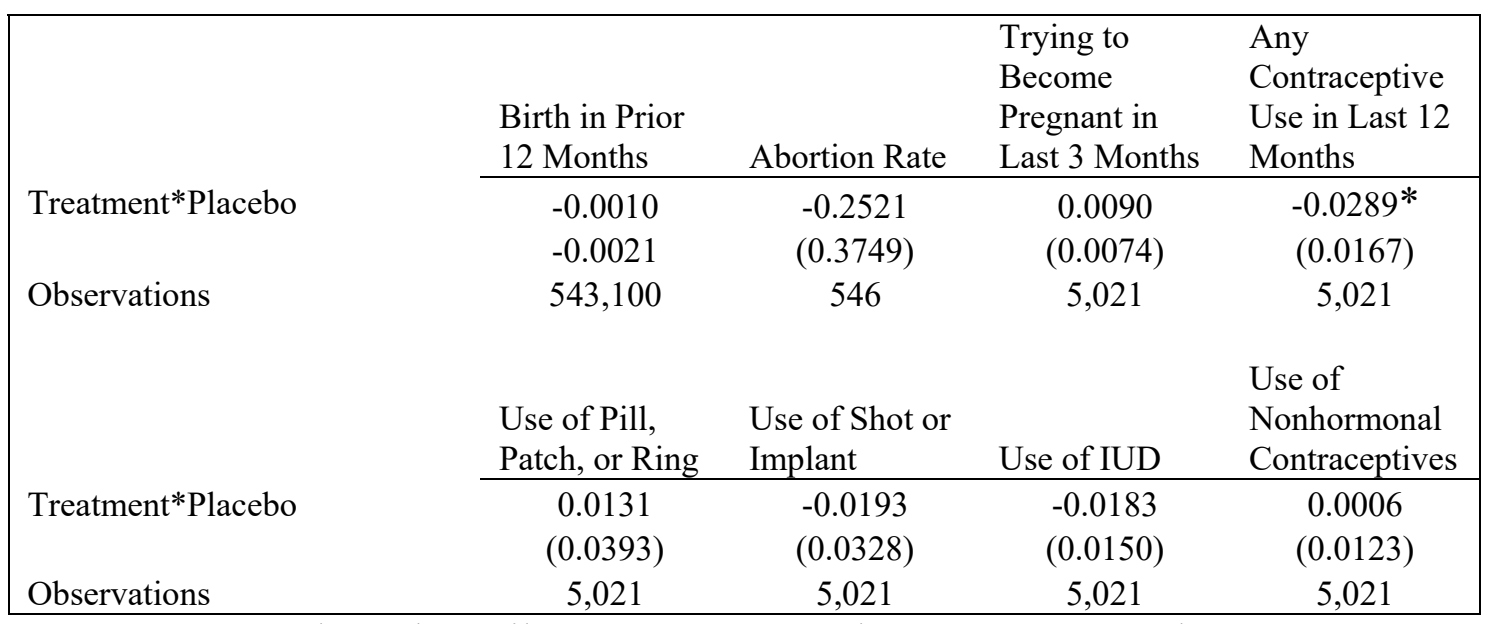

Source: January 2008 through April 2010 1-year ACS data, 2006-2009 and 2012-2013 CDC abortion surveillance data, and 2006-2010 NSFG data. Notes: Shown are coefficients estimated from the specification of the determinants of fertility and related outcomes. Each coefficient estimate reflects results from a single regression. Regressions are estimated using population weights. ACS specifications include state, year, and age fixed effects, national and state-year trends, as well as individual demographic controls, and the age-specific state-year unemployment rate, and standard errors are clustered at the state level. The ACS sample includes all women from all U.S. states and the District of Columbia living in households or college dormitories who are not active duty military ages 20-30, excluding women ages 26 and 27. CDC abortion surveillance specifications include state, year, and age group fixed effects, national and stateyear trends, as well as state-year-age-group demographic and economic controls, and standard errors are clustered at the state level. The CDC abortion surveillance sample includes abortion rates for women ages 15-29. NSFG specifications include year and age fixed effects and national year trends, as well as individual demographic controls. The NSFG sample includes all women ages 16-30, excluding women ages 19,26, and 27. Standard errors in parentheses, *** $\mathrm{p}<0.01,{ }^{* *} \mathrm{p}<0.05,{ }^{*} \mathrm{p}<0.1$. Numbers of observations for regression of birth in prior 12 months are rounded to the nearest hundred. 
Figures

Fig. 1 Proportion of Women who Gave Birth in the Prior 12 Months by Age Group and Year

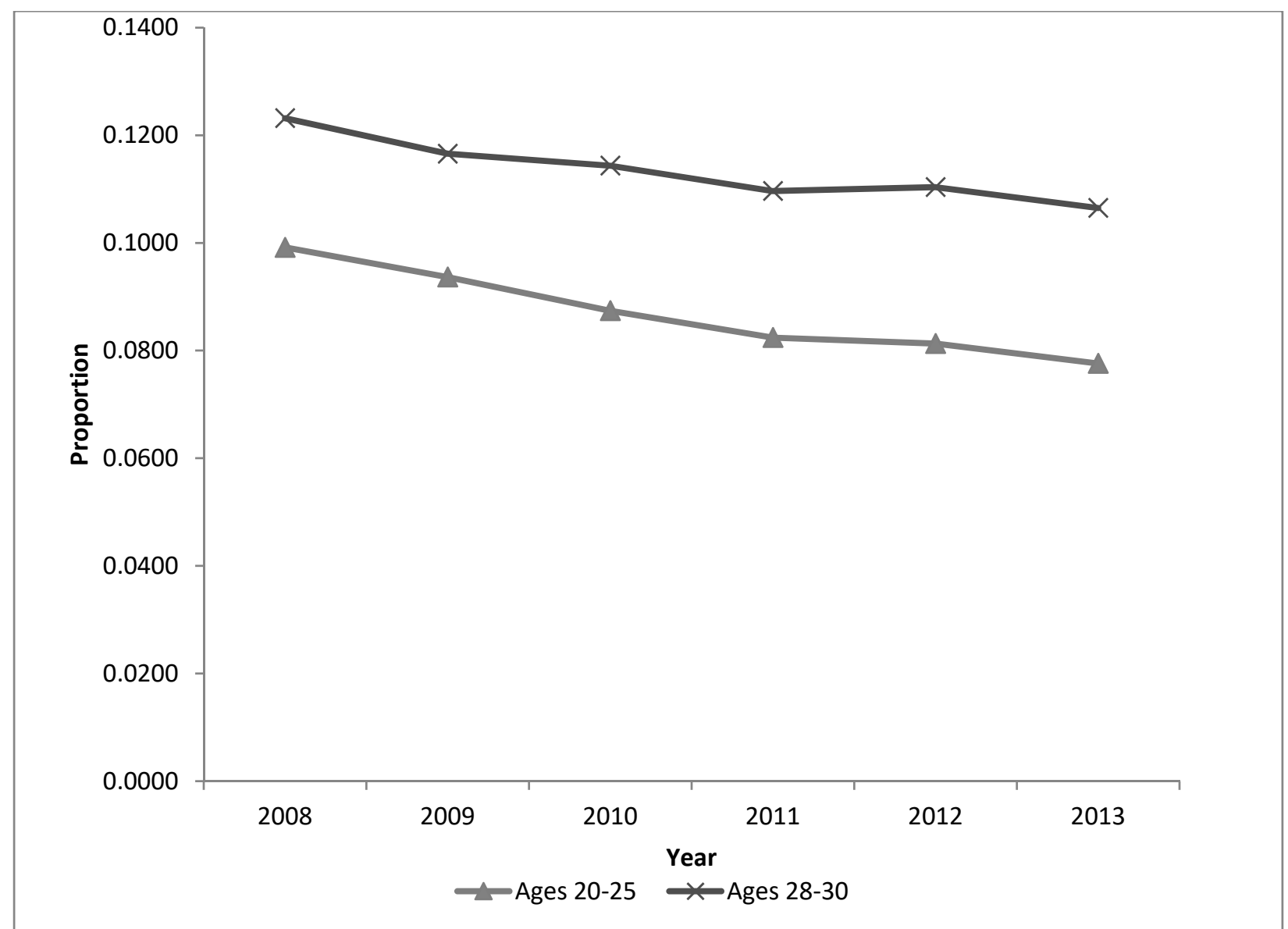

Source: 2008 through 2013 1-year ACS data. Note: The sample includes women from all U.S. states and the District of Columbia living in households or college dormitories who are not active duty military. 
Fig. 2 CDC Abortion Surveillance Abortion Rate by Age Group and Year

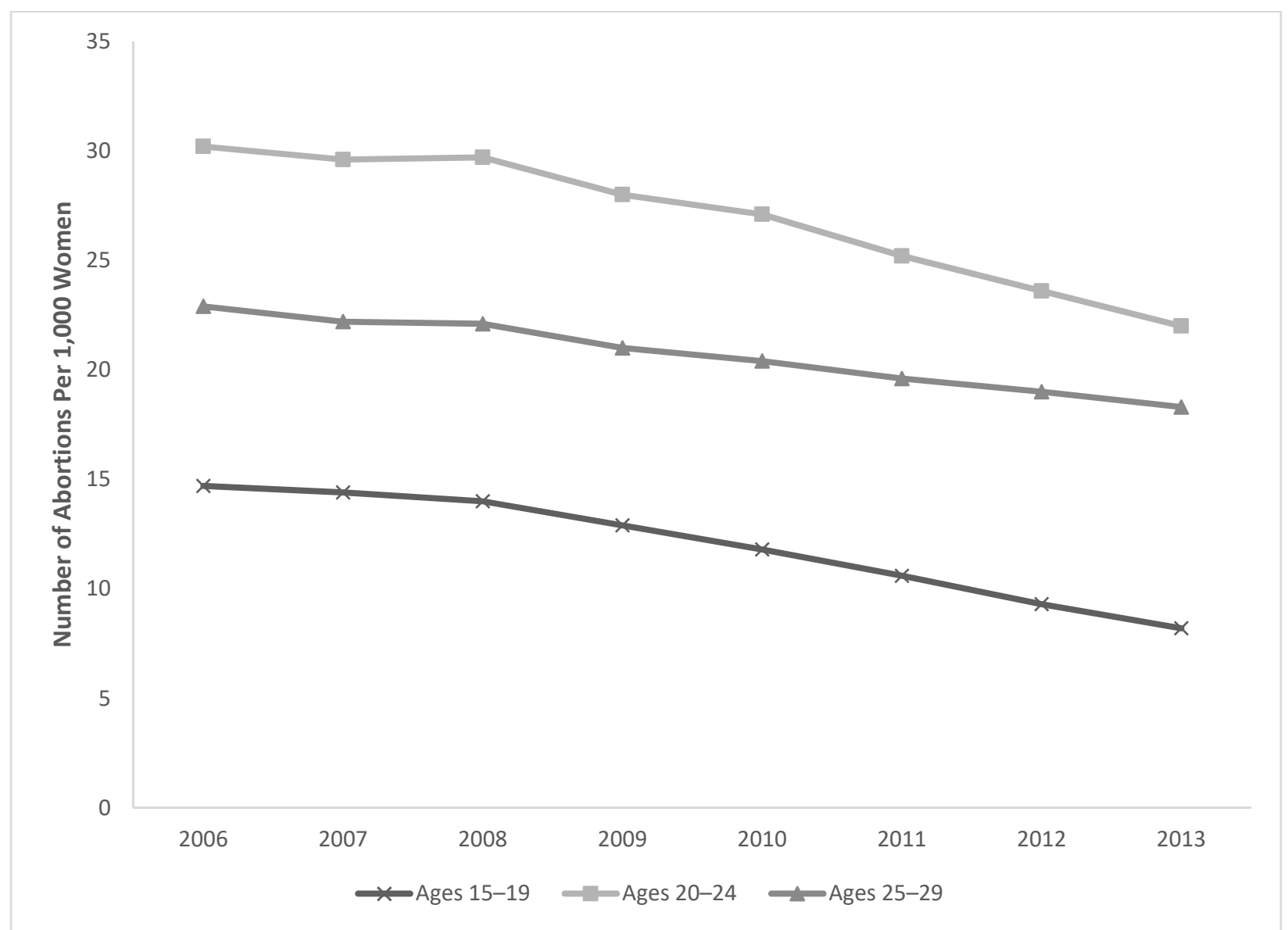

Sources: Jatlaoui et al. (2016). Notes: Excludes 10 reporting areas (California, District of Columbia, Florida, Louisiana, Maine, Maryland, New Hampshire, Vermont, West Virginia, and Wyoming) that did not report, did not report by age, or did not meet reporting standards for one or more years. 
Appendix

Appendix 1: ACS Pre-Trends Regression Results

\begin{tabular}{|c|c|c|c|c|c|c|}
\hline \multirow[b]{3}{*}{ Treatment*Year } & \multicolumn{6}{|c|}{ Birth in Prior 12 Months } \\
\hline & All & $\begin{array}{l}\text { White, Not } \\
\text { Hispanic }\end{array}$ & $\begin{array}{l}\text { Black, Not } \\
\text { Hispanic }\end{array}$ & Hispanic & Rural & Metro \\
\hline & $\begin{array}{c}-0.0036 \\
(0.0025)\end{array}$ & $\begin{array}{l}-0.0041 \\
(0.0026)\end{array}$ & $\begin{array}{c}-0.0044 \\
(0.0043)\end{array}$ & $\begin{array}{l}-0.0006 \\
(0.0066)\end{array}$ & $\begin{array}{l}-0.0041 \\
(0.0026)\end{array}$ & $\begin{array}{l}-0.0044 \\
(0.0043)\end{array}$ \\
\hline Observations & 543,100 & 355,200 & 57,700 & 84,200 & 355,200 & 57,700 \\
\hline & $\begin{array}{l}\text { Married in } \\
\text { Prior } 12 \\
\text { Months }\end{array}$ & $\begin{array}{c}\text { Married } \\
\text { and Gave } \\
\text { Birth in } \\
\text { Prior } 12 \\
\text { Months }\end{array}$ & & & & \\
\hline Treatment*Year & $\begin{array}{l}-0.0007 \\
(0.0017)\end{array}$ & $\begin{array}{c}0.0005 \\
(0.0004)\end{array}$ & & & & \\
\hline Observations & 543,100 & 543,100 & & & & \\
\hline
\end{tabular}

Source: January 2008 through April 2010 1-year ACS data. Notes: Shown are coefficients estimated from the specification of the determinants of the probability of having given birth in the prior 12 months, having married in the prior 12 months, or having married and having given birth in the prior 12 months. Each coefficient estimate reflects results from a single regression. Regressions are estimated using population weights. Specifications include state, year, and age fixed effects, national and state-year trends, as well as individual demographic controls, and the age-specific state-year unemployment rate. The sample includes all women from all U.S. states and the District of Columbia living in households or college dormitories who are not active duty military ages 20-30, excluding women ages 26 and 27, except as noted. Robust standard errors clustered at the state level in parentheses, ${ }^{* * *} \mathrm{p}<0.01,{ }^{* *} \mathrm{p}<0.05,{ }^{*} \mathrm{p}<0.1$. Numbers of observations are rounded to the nearest hundred. 
Appendix 2: CDC Abortion Surveillance and NSFG Pre-Trends Regression Results

\begin{tabular}{|c|c|c|c|c|}
\hline & $\begin{array}{l}2006-2009 \text { and } \\
2012-2013 \\
\text { Abortion Rate, } \\
\text { Ages } 15-29\end{array}$ & $\begin{array}{l}\text { Trying to } \\
\text { Become } \\
\text { Pregnant in } \\
\text { Last } 3 \text { Months }\end{array}$ & $\begin{array}{l}\text { Any } \\
\text { Contraceptive } \\
\text { Use in Last } 12 \\
\text { Months }\end{array}$ & \\
\hline Treatment*Year & $\begin{array}{l}-0.1279 \\
(0.2049)\end{array}$ & $\begin{array}{l}-0.0112 \\
(0.0082)\end{array}$ & $\begin{array}{c}0.0081 \\
(0.0164)\end{array}$ & \\
\hline \multirow[t]{2}{*}{ Observations } & 546 & 5,021 & 5,021 & \\
\hline & $\begin{array}{l}\text { Use of Pill, } \\
\text { Patch, or Ring }\end{array}$ & $\begin{array}{l}\text { Use of Shot or } \\
\text { Implant }\end{array}$ & Use of IUD & $\begin{array}{c}\text { Use of } \\
\text { Nonhormonal } \\
\text { Contraceptives }\end{array}$ \\
\hline Treatment*Year & $\begin{array}{l}-0.0164 \\
(0.0152)\end{array}$ & $\begin{array}{l}-0.0065 \\
(0.0067)\end{array}$ & $\begin{array}{c}0.0020 \\
(0.0056)\end{array}$ & $\begin{array}{c}0.0274 \\
(0.0180)\end{array}$ \\
\hline Observations & 5,021 & 5,021 & 5,021 & 5,021 \\
\hline
\end{tabular}

Source: 2006-2009 and 2012-2013 CDC abortion surveillance and 2006-2010 NSFG data. Notes: Shown are coefficients estimated from the specification of the determinants of fertility and related outcomes. Each coefficient estimate reflects results from a single regression. Regressions are estimated using population weights. CDC abortion surveillance specifications include state, year, and age group fixed effects, national and state-year trends, as well as stateyear-age-group demographic and economic controls, and standard errors are clustered at the state level. The CDC abortion surveillance sample includes abortion rates for women ages 15-29. NSFG specifications include year and age fixed effects and national year trends, as well as individual demographic controls. The NSFG sample includes all women ages 16-30, excluding women ages 19, 26, and 27. Standard errors in parentheses, ${ }^{* * *} \mathrm{p}<0.01,{ }^{* *} \mathrm{p}<0.05,{ }^{*} \mathrm{p}<0.1$. 
Appendix 3: Estimates of Reductions in Fertility Associated with the Young Adult Provision

\begin{tabular}{|c|c|c|c|}
\hline \multicolumn{4}{|c|}{ Assuming same fertility rates across treated and untreated } \\
\hline \multirow{6}{*}{$\begin{array}{l}\text { Group } \\
\text { New Female Insurance Enrollees Ages 20-25 } \\
\text { All Other Females Ages 20-25 } \\
\text { TOTAL }\end{array}$} & \multicolumn{3}{|l|}{ Pre-Reform } \\
\hline & \multirow[b]{2}{*}{$\mathrm{N}$} & \multicolumn{2}{|l|}{ Birth } \\
\hline & & Rate & Births \\
\hline & $1,320,252$ & 0.0952 & 125,688 \\
\hline & $11,623,391$ & 0.0952 & $1,106,547$ \\
\hline & $12,943,643$ & 0.0952 & $1,232,235$ \\
\hline \multirow{5}{*}{$\begin{array}{l}\text { Group } \\
\text { New Female Insurance Enrollees Ages 20-25 } \\
\text { All Other Females Ages 20-25 } \\
\text { TOTAL }\end{array}$} & \multicolumn{3}{|l|}{ Reform } \\
\hline & $\mathrm{N}$ & $\begin{array}{l}\text { Birth } \\
\text { Rate }\end{array}$ & Births \\
\hline & $1,320,252$ & 0.0021 & 2,723 \\
\hline & $11,623,391$ & 0.0952 & $1,106,547$ \\
\hline & $12,943,643$ & 0.0857 & $1,109,270$ \\
\hline \multicolumn{4}{|c|}{ Assuming treated fertility rate approximately double untreated fertility rate } \\
\hline \multirow{5}{*}{$\begin{array}{l}\text { Group } \\
\text { New Female Insurance Enrollees Ages 20-25 } \\
\text { All Other Females Ages 20-25 } \\
\text { TOTAL }\end{array}$} & \multicolumn{3}{|c|}{ Pre-Reform } \\
\hline & $\mathrm{N}$ & $\begin{array}{l}\text { Birth } \\
\text { Rate }\end{array}$ & Births \\
\hline & $1,320,252$ & 0.1850 & 244,247 \\
\hline & $11,623,391$ & 0.0850 & 987,988 \\
\hline & $12,943,643$ & 0.0952 & $1,232,235$ \\
\hline \multirow{5}{*}{$\begin{array}{l}\text { Group } \\
\text { New Female Insurance Enrollees Ages 20-25 } \\
\text { All Other Females Ages 20-25 } \\
\text { TOTAL }\end{array}$} & \multicolumn{3}{|l|}{ Reform } \\
\hline & $\mathrm{N}$ & $\begin{array}{l}\text { Birth } \\
\text { Rate }\end{array}$ & Births \\
\hline & $1,320,252$ & 0.0919 & 121,282 \\
\hline & $11,623,391$ & 0.0850 & 987,988 \\
\hline & $12,943,643$ & 0.0857 & $1,109,270$ \\
\hline
\end{tabular}

Notes: Calculations use the estimate of the 2011 U.S. female population aged 20-25 of 12.9 million (U.S. Census Bureau (2014), the finding by Akosa Antwi, Moriya, and Simon (2013) that the provision was associated with a 10.2 percentage point increase in parent employersponsored insurance dependent coverage over October-November 2011, and this paper's finding that the provision was associated with a 0.95 percentage point decrease in the probability of having given birth in the prior 12 months. 